Document downloaded from:

http://hdl.handle.net/10251/47176

This paper must be cited as:

España Giner, J. M.; Boronat, T.; Garcia-Sanoguera, D.; et al. (2013). Use of atmospheric plasma treatment to improve adhesion properties of sodium ionomer sheets. Surface and Coatings Technology. 218:1-6. doi:10.1016/j.surfcoat.2012.12.016.

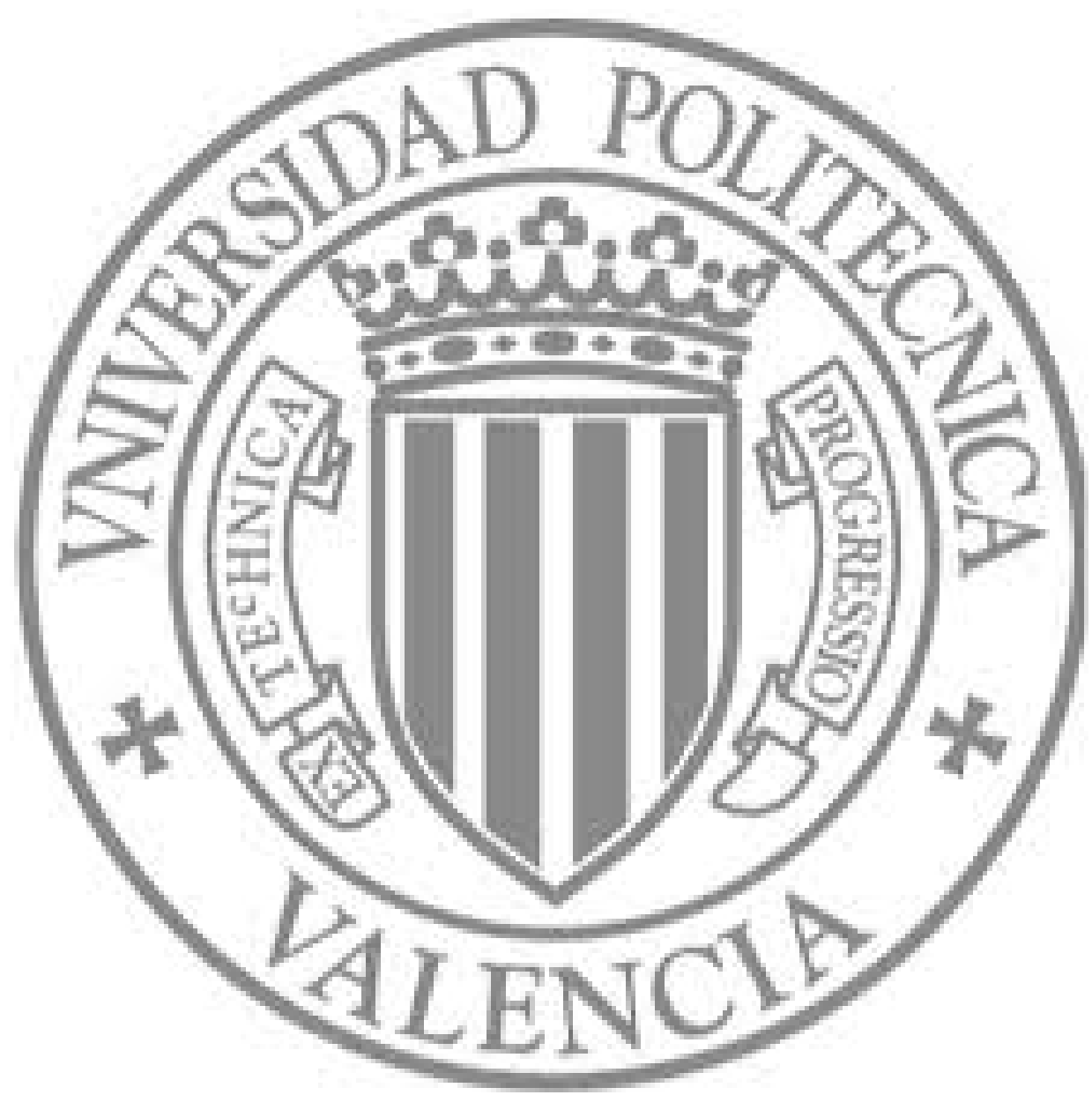

The final publication is available at

http://dx.doi.org/10.1016/j.surfcoat.2012.12.016

Copyright Elsevier 


\title{
"Use of atmospheric plasma treatment to improve adhesion properties of sodium ionomer sheets"
}

\author{
J.M.España ${ }^{1}$, T. Boronat, D. García-Sanoguera, J. López, R. Balart
}

\author{
Instituto de Tecnología de Materiales (ITM) \\ Universitat Politècnica de València (UPV) \\ Plaza Ferrandiz y Carbonell 1, 03801, Alcoy, Alicante (Spain)
}

\begin{abstract}
Polyolefins are characterized by having a low surface energy due to their nonpolar nature, in the case of some ionomers, the base component is a polyolefin, thus relative poor adhesion properties are expected. For this reason, polyolefin-based sodium ionomers posses low adhesion properties. It is widely known that for many industrial applications, such as coatings, paintings and formation of adhesive bonds, a high surface energy is required in order to provide good surface adhesion; for this reason the use of ionomers in these applications requires a previous surface treatment. In this paper surface treatment by atmospheric plasma has been used to provide surface activation to polyolefin-based sodium ionomers in order to improve their low intrinsic adhesion properties. This work has focused on the analysis of the influence of main process variables such as treatment rate and distance between nozzle and substrate to observe the improvement of adhesion properties at ionomer-polycarbonate adhesion joints subjected to shear and T-peel tests.
\end{abstract}

\footnotetext{
${ }^{1}$ Corresponding author: Jose Manuel España Giner email: joesgi1@upvnet.upv.es telf/fax number: +0034966528433
} 
Keywords: Plasma, ionomers, adhesion, mechanical properties, surface modification. 


\section{1.- Introduction}

In the last years the use of ionomers is continuously increasing because they show the same properties as many polyolefins such as easy processing, good chemical stability and inertness, balanced electrical insulation, etc. but in addition ionomers posses higher mechanical properties, higher strength and higher hardness. They are also characterized by possessing a low surface energy due to their low polar nature, which fully explains the chemical inertness and the lack of external migrations. These characteristics make ionomers suitable for orthodontic applications, food packaging and medical supplies $[1,2]$.

The use of ionomers requires, in many cases, formation of adhesion joints to other materials such as metals and other technical polymers. Nevertheless, as ionomers are characterized by low surface free energy, mechanical performance of adhesion joints with ionomers is poor. For this reason it is necessary to selectively modify surface properties in order to improve the low intrinsic adhesion nature of ionomers, mainly based on polyolefin polymers. There is a great variety of surface processes with which the adhesive properties of a polymer can be improved without changing the bulk material. They can be grouped into chemical, physical or combined processes [3-5]. Generally, when using chemical processes, the polymer surface is exposed to different chemical agents such as acids, monomers, oxidizing compounds, etc. to promote some chemical reactions that, in general terms, lead to surface abrasion and insertion of different functionalities. In many cases it is necessary the total immersion of the polymer part to be successfully treated in a chemical bath which contains the appropriate chemical agents to produce superficial activation [6-9]. The major drawback of using these chemical processes is the aqueous waste which may contain potentially contaminating chemical components [10-12]. 
As an environmentally friendly solution to conventional chemical processes, we can find some physical processes to modify the topmost layers of a polymer substrate. These processes are characterized by exposing the polymer surface to different types of radiation, such as ultraviolet radiation, $\gamma$ radiation, $\beta$ radiation, laser, plasmas, etc [13, 14]. In recent years, the use of atmospheric plasma has become an interesting alternative for surface modification of polymer substrates. This is more efficient than chemical processes; it is faster and environmentally friendly [15-18]. The highly active species in the plasma gas promote chain scission and subsequent free radical formation which is responsible for two different main effects: on the one hand low molecular weight oxidized material (LMWOM) resulting from reaction of some free radicals and air promote changes in surface topography $[6,7,19,20]$; on the other hand free radicals on the surface tend to react with the oxygen which is present in both air plasma and subsequent exposure of plasma-treated materials to air.[20, 21]. A great advantage of using the atmospheric plasma is that it can be used on a continuous basis, so it could be easy adapted into a production line.

The main objective of this work is the use of atmospheric plasma to improve surface wettability of polyolefin-based ionomer sheets, in order to improve the mechanical properties of the adhesive bonds to polycarbonate substrates. This work is focused on optimizing the typical processing parameters of atmospheric plasma treatment (nozzle-substrate distance and treatment rate) to improve the low intrinsic wettability. The effect of these process variables is evaluated using T-peel and shear tests. Later, scanning electron microscopy is used to evaluate the effect of the atmospheric plasma treatment on surface topography of fractured adhesion joints.

\section{2.- Experimental}




\section{1.- Materials}

The base ionomer was a commercial grade Surlyn PC-100 supplied by DuPont (DuPont, Barcelona, Spain). This consists on an ethylene and methacrylic acid copolymer with certain amounts of sodium cations. This material is supplied in pellet form and it is especially suitable for injection molding. It has a melt flow index (MFI at $190{ }^{\circ} \mathrm{C}$ and $2.16 \mathrm{~kg}$ ) of $1.09 \mathrm{~g} / 10 \mathrm{~min}$. Ionomer sheets sizing $160 \times 160 \times 2 \mathrm{~mm}^{3}$ were obtained by injection molding Mateu-Solé injection machine, mod. 270/5 (Mateu-Solé S.A., Barcelona, Spain). Commercial sheets of polycarbonate PC Lexan Excel *D were supplied by Sabic Innovation Plastics Spain S.COM.P.A. (Sabic Innovation Plastics, Murcia, Spain). These PC sheets were cut according to the dimensions of the peel tests that were performed in this study. Polycarbonate sheets were used to provide stiffness adhesion joints as ionomer is characterized by relatively high flexibility.

The adhesive used was the "Ceys Montack Transparente", chosen for its clean, clear finish in agreement with the pieces of the adhesive joints. It is a neoprene based adhesive, of high initial tack and high final strength of its unions. The adhesive was supplied by Ceys (Ceys S.A., Barcelona, España).

\section{2.- Atmospheric plasma treatment}

Ionomer sheets were subjected to atmospheric plasma. The plasma generator operates at 50/60 Hz, $230 \mathrm{~V}$ and $16 \mathrm{~A}$. This plasma equipment was supplied by Plasmatreat, mod. FG 3001 (Plasmatreat GmbH, Steinhagen, Germany) equipped with a rotational nozzle. This equipment woks by injecting compressed air at a pressure of 2 bars. The effect of the plasma treatment was evaluated in terms of the nozzle-sample distance $(6,10,14$ and $20 \mathrm{~mm})$ and the treatment rate $(100,300,500,700$ and 1000 $\left.\mathrm{mm} \cdot \mathrm{s}^{-1}\right)$. 


\section{3.- Contact Angle Measurements}

Contact angle measurements were done with an optical goniometer EasyDrop Standard mod. FM140 110/220 V, 50/60 Hz (Krüss GmbH, Hamburg, Germany). The goniometer is equipped with the software Drop Shape Analysis SW21 for quantitative evaluation of wettability. Measurements of contact angles were carried out 5 min after the plasma treatment for all samples and the maximum error did not exceed $\pm 3 \%$.

\section{4.- Surface characterization}

The surface morphology of the treated ionomer sheets with atmospheric plasma was analyzed with a scanning electron microscope (SEM) supplied by FEI, model Phenton (FEI Company, Eindhoven, The Netherlands) with an acceleration voltage of $5 \mathrm{kV}$. Before each measurement, samples were subjected to a sputtering process with a platinum-aurum allow with a sputter coater model SC7620 (Quorum Technologies, Kent, UK).

\section{5.- Characterization of adhesion joints}

T-peel and shear tests were carried out in a universal testing machine ELIB 30 (S.A.E. Ibertest, Madrid, Spain). T-peel tests were performed according to the UNE-EN ISO 1895 standard. The adhesion joint length for the T-peel test was $150 \mathrm{~mm}$ and the crosshead rate was set to $300 \mathrm{~mm} \mathrm{~min}^{-1}$.

In addition to T-peel tests, mechanical response of ionomer-PC adhesion joints was tested in shear mode following the guidelines of the UNE-EN ISO 13445. Samples

sizing $25 \times 25 \mathrm{~mm}^{2}$ joined to a total length of $12 \mathrm{~mm}$ and the crosshead rate was set to $1.5 \mathrm{~mm} \mathrm{~min}^{-1}$. 


\section{3.- Results and discussion}

\subsection{The effect of atmospheric plasma on ionomer-PC adhesion joints}

The action of plasma on the ionomer sheets is the interaction of the ionized species from the atmosphere that are generated by plasma on the sheet's surface, increasing the wettability of the ionomer surface. This increase depends on the processing variables of the atmospheric plasma during its application to the surface. We can optimize the atmospheric plasma parameters (plasma speed and nozzle-substrate distance) analyzing the variation of contact angles, which indicates the extent of hydrophilicity of treated surface.

Table 1 show values for contact angle on the ionomer sheets treated with atmospheric plasma at various nozzle-substrate distances and at various plasma speeds, using water like contact angle. The contact angle measurements allow us to study changes in wettability of ionomer sheets as a function of application conditions in the plasma treatment.

\section{Table 1}

The analysis of the data contained in the table 1 shows that in general, for any nozzle-substrate distance, the values of contact angles decreases as treatment speed decreases too, achieving a minimum value at low speeds. Likewise, comparing the results observed for every distance at fixed speed, when distance increases, so does the contact angle, decreasing the wettability. It was found that at distance of $6 \mathrm{~mm}$ and a speed of $100 \mathrm{~mm} \cdot \mathrm{s}^{-1}$, there was a $68 \%$ decrease in the contact angle, at $10 \mathrm{~mm}$ with the same speed, there was a $44 \%$ decrease, at $14 \mathrm{~mm}$, the contact angle decreases by $24 \%$ and at $20 \mathrm{~mm}$, there is a decrease of $22 \%$. Is possible that this tendency will be related 
with the results of adhesion tests, due that the adhesion properties depends on the surface wettability.

In order to see the effectiveness of the atmospheric plasma treatment on sodium ionomer sheets, T-peel tests were performed on the treated samples at different conditions. In previous studies, was demonstrated an improve of surface energy of ionomer sheets after atmospheric plasma treatment (DOI 10.1002/pen.23218).

In this test the mechanical response of the adhesive joints for different conditions of plasma treatment rate and nozzle-substrate distance is evaluated as there is a direct relationship between wettability and adhesion properties. Samples with different atmospheric plasma treatment conditions were joined to polycarbonate substrates to a two T-shaped sample and the curing time of the adhesive was 24 hours to ensure optimum mechanical performance.

Fig. 1 shows the T-peel force values for ionomer-PC adhesion joints with different treatment conditions regarding the plasma application rate and the nozzlesubstrate distance. When we compare the values obtained with the initial value of untreated samples $(8.5 \mathrm{~N})$, we observe a clear increase in T-peel force with a maximum value of $57.2 \mathrm{~N}$ for a treatment rate of $100 \mathrm{~mm} \mathrm{~s}^{-1}$ and a nozzle-substrate distance of 6 $\mathrm{mm}$. This represents a percentage increase of over $650 \%$. On increasing the nozzlesubstrate distance and the plasma treatment rate, the T-peel force value decreases up to a minimum value of $16.2 \mathrm{~N}$ for a nozzle-substrate distance of $20 \mathrm{~mm}$ and a plasma rate of $1000 \mathrm{~mm} \mathrm{~s}^{-1}$, but even in this case the T-peel force is remarkably increased (190\%) if compared to the untreated sample. These results confirm that the adhesive properties of the surfaces of the samples improve with the effect of plasma treatment. As stated by previous results, aggressive conditions (short nozzle-substrate distance and low plasma treatment rate) lead to a remarkable increase in adhesion properties whereas the use of 
less aggressive conditions (large nozzle-substrate distance and high plasma treatment rate) is still useful to provide good adhesion properties but lower than those obtained with aggressive conditions.

\section{Figure 1}

Mechanical performance of ionomer-PC adhesion joints has also been tested in shear mode. In this test the influence of the test parameters has also been studied, this is to say, treatment rate and nozzle-substrate distance. In Fig. 2 we can see the results of maximum force in a 3D graph showing the influence of the nozzle-substrate distance and plasma treatment rate on shear force. This test shows a similar trend to that of the Tpeel test. It can be seen that the maximum value of shear force $(307.9 \mathrm{~N})$ corresponds to the most aggressive conditions tested in this work: nozzle-substrate distance of $6 \mathrm{~mm}$ and plasma treatment rate of $100 \mathrm{~mm} \mathrm{~s}^{-1}$. This value represents almost a percentage increase of $1000 \%$ since the shear force of the untreated ionomer-PC is close to $27.6 \mathrm{~N}$. Once again, the minimum value of shear force is achieved with the least aggressive conditions tested in this work: nozzle-substrate distance of $20 \mathrm{~mm}$ and plasma treatment rate of $1000 \mathrm{~mm} \mathrm{~s}^{-1}$ but even in these relatively low aggressive conditions, a remarkable increase in the shear force is obtained $(95.7 \mathrm{~N}$ which represents a percentage increase of about $300 \%$ ).

\section{Figure 2}

3.2. Analysis of the morphology of the fracture surfaces of the adhesive bonds. 
The adhesion of the two substrates can be assessed by simply performing a break test of the adhesive bond. When designing an adhesive bond it is intended that in case of breaking, failure will always take place through the adhesive, although this will always depend on its adhesive characteristics. To evaluate the extend of the adhesion-cohesion failure, fractured surfaces from T-peel and shear tests were evaluated by scanning electron microscopy.

In the SEM images in Figure 3, we can observe the evolution of the fracture surface adhesion joints from T-peel tests for different nozzle-substrate distances and an aggressive plasma treatment rate of $100 \mathrm{~mm} \mathrm{~s}^{-1}$. Fig. 3a shows the roughest surface which indicates good adhesion behavior (mainly cohesive adhesive failure); the failure took place because of the adhesive breakage. As the nozzle-substrate distance increases, we observe more smooth surfaces as the wettability of the ionomer is lower since the surface modification produced by the action of the plasma is lower, so it will have less wettability, and this, in turn, leads to lower adhesion properties and a intermediate adhesive-cohesive failure type. As surface activation by plasma treatment is lower, interactions between the ionomer surface and the adhesive are lower and this enables adhesive removing during the T-peel test. So it is confirmed that for smaller nozzlesubstrate distances the adherence will be more favored as surface activation of ionomer occurs in a greater extent than for less aggressive conditions.

\section{Figure 3}

By comparing the plasma treatment rate, in Fig. 4, for a constant nozzlesubstrate distance of $10 \mathrm{~mm}$, we can observe how the surface appearance changes depending on the plasma treatment rate. It is noted that at low rates, Fig. 4a, a cohesive 
failure occurs in the adhesive joint, and large bubbles which are characteristic of the adhesive structure appear. While at higher speeds, image (b), the breaking of the adhesive is produced by combining, cohesive failure and adhesive failure in the face of the ionomer. For high treatment plasma speed, the effect of the treatment cannot produce the necessary anchoring for the adhesive to strongly stick to the surface of the ionomer, and therefore the wettability of the surface under these conditions will be lower than at lower plasma speeds.

\section{Figure 4}

The same behaviour is detected trough SEM analysis of fractured samples from shear tests (Fig. 5). For short nozzle-substrate distances and low plasma treatment rates (aggressive conditions), we observe a typical mainly cohesive fracture characterized by a rough surface. This rough surface is formed during the shear test; as the shear stress increases, the adhesive in the adhesion joint suffers some deformation but it is highly bonded to the ionomer substrate, finally the adhesion occurs in the adhesive leading to a typical mainly cohesive failure. This high roughness morphology corresponds to stronger joints, since the force required to separate the joint is the highest as described previously. As the nozzle-substrate distance increases, the roughness of the fractured surface decreases. This can be explained by taking into account that the effects of the plasma treatment are lower as the nozzle-substrate distance increases, so that, adhesiveionomer interactions are not as strong and this leads to less deformation as some adhesive is removed from the adhesive-ionomer interface when shear stress is applied (

Fig. 5b and Fig. 5c); these cases are characterized by a balanced adhesive-cohesive failure type. In Fig. 5d, which corresponds to the maximum nozzle-substrate distance 
(20 $\mathrm{mm}$ ) we observe a relatively smooth surface if compared with previous images. The adhesive is weakly bonded to the ionomer surface and a great amount of adhesive is separated from the ionomer surface after the shear test leading to a mainly adhesive failure type.

\section{Figure 5}

The influence of the plasma treatment type can be observed in Fig. 6 as it shows SEM photographs of fractured surfaces (shear mode) of ionomer-PC adhesion joints with the following plasma conditions: constant nozzle-substrate distance of $10 \mathrm{~mm}$ and varying plasma treatment rate of $100 \mathrm{~mm} \mathrm{~s}^{-1}$ (Fig. 6a) and $1000 \mathrm{~mm} \mathrm{~s}^{-1}$ (Fig. 6b). Low plasma treatment rates such as $100 \mathrm{~mm} \mathrm{~s}^{-1}$ (more aggressive) leads to a highly rough surface thus indicating a mainly cohesive failure type whereas high plasma treatment rates (less aggressive) of $1000 \mathrm{~mm} \mathrm{~s}^{-1}$, leads to an adhesive-cohesive failure mechanism with clear evidences of adhesive failure.

\section{Figure 6}

\section{4.- Conclusions}

The mechanical properties of ionomer-polycarbonate adhesion joints are remarkably increased by using atmospheric plasma techniques with pressurized air. There is a direct relationship between wettability and mechanical performance of ionomer-polycarbonate adhesion joints. It has been observed that for short nozzlesubstrate distances $(6 \mathrm{~mm})$, adhesive-surface interactions are strong, requiring a greater force to separate the joint, while the use of large distances $(20 \mathrm{~mm})$ leads to weaker 
interactions, making it easier to break the adhesion joint. With regard to the plasma treatment rate, the best results are obtained for the lowest rate $\left(100 \mathrm{~mm} \cdot \mathrm{s}^{-1}\right)$ whereas as we increase the plasma treatment rate adhesive-ionomer interactions weaken. Scanning electron microscopy (SEM) is a useful technique to determine the failure type of the adhesion joints (adhesive, cohesive or a combination). Cohesive failure is characterized by rough surfaces and adhesive failure can be detected trough smooth areas. Finally it is possible to conclude that atmospheric plasma is an efficient technique from a technical point of view and also environmentally friendly as no wastes are generated.

\section{Acknowledgements}

This work is part of the project IPT-310000-2010-037, "ECOTEXCOMP: Research and development of textile structures useful as reinforcement of composite materials with marked ecological character" funded by the "Ministerio de Ciencia e Innovacion", with an aid of 189540.20 euros, within the "Plan Nacional de Investigación Científica, Desarrollo e InnovaciónTecnológica 2008-2011” and funded by the European Union through FEDER funds, Technology Fund 2007-2013, Operational Programme on $\mathrm{R}+\mathrm{D}+\mathrm{i}$ for and on behalf of the companies." Also Generalitat Valenciana Ref.: ACOMP/2012/087 is acknowledged for financial support.

J.M. España wants to thank the Polytechnic University of Valencia (UPV) for their financial support through an FPI-UPV grant.

\section{References}

[1] R.D. Lundberg, P.K. Agarwal, Indian Journal of Technology, 31 (1993) 400-418.

[2] G. Bonizzoni, E. Vassallo, Vacuum, 64 (2002) 327-336.

[3] M. Pascual, O. Calvo, L. Sanchez-Nacher, M. Angeles Bonet, D. Garcia-Sanoguera, R. Balart, Journal of Applied Polymer Science, 114 (2009) 2971-2977. 
[4] N. De Geyter, R. Morent, C. Leys, Surface and Interface Analysis, 40 (2008) 608611.

[5] R.M. Sanchis, O. Calvo, L. Sanchez, D. Garcia, R. Balart, Journal of Polymer Science Part B-Polymer Physics, 45 (2007) 2390-2399.

[6] C. Borcia, G. Borcia, N. Dumitrascu, Journal of Optoelectronics and Advanced Materials, 10 (2008) 675-679.

[7] I. Novak, M. Steviar, I. Chodak, I. Krupa, T. Nedelcev, M. Spirkova, M.M. Chehimi, J. Mosnacek, A. Klienova, Polymers for Advanced Technologies, 18 (2007) 97-105.

[8] R.M. Thurston, J.D. Clay, M.D. Schulte, Journal of Plastic Film \& Sheeting, 23 (2007) 63-78.

[9] L. Zhu, W. Teng, H. Xu, Y. Liu, Q. Jiang, C. Wang, Y. Qiu, Surface \& Coatings Technology, 202 (2008) 1966-1974.

[10] X. Chen, L. Yao, J. Xue, D. Zhao, Y. Lan, X. Qian, C.X. Wang, Y. Qiu, Applied Surface Science, 255 (2008) 2864-2868.

[11] H. Krump, I. Hudec, M. Jasso, E. Dayss, A.S. Luyt, Applied Surface Science, 252 (2006) 4264-4278.

[12] S.M. Gawish, A.M. Ramadan, C.E. Cornelius, M.A. Bourham, S.R. Matthews, M.G. McCord, D.M. Wafa, F. Breidt, Textile Research Journal, 77 (2007) 92-104.

[13] S. Guimond, M.R. Wertheimer, Journal of Applied Polymer Science, 94 (2004) 1291-1303.

[14] X.W. Yang, M. Moravej, G.R. Nowling, J.P. Chang, R.F. Hicks, Ieee Transactions on Plasma Science, 33 (2005) 294-295.

[15] Y. Kusano, H. Mortensen, B. Stenum, S. Goutianos, S. Mitra, A. GhanbariSiahkali, P. Kingshott, B.F. Sorensen, H. Bindslev, International Journal of Adhesion and Adhesives, 27 (2007) 402-408.

[16] Y. Kusano, H. Mortensen, B. Stenum, P. Kingshott, T.L. Andersen, P. Brondsted, J.B. Bilde-Sorensen, B.F. Sorensen, H. Bindslev, Plasma Processes and Polymers, 4 (2007) S455-S459.

[17] F. Leroux, A. Perwuelz, C. Campagne, N. Behary, Journal of Adhesion Science and Technology, 20 (2006) 939-957.

[18] M. Moravej, R.F. Hicks, Chemical Vapor Deposition, 11 (2005) 469-476.

[19] C. Borcia, G. Borcia, N. Dumitrascu, Applied Physics a-Materials Science \& Processing, 90 (2008) 507-515.

[20] D.M. Wafa, F. Breidt, S.M. Gawish, S.R. Matthews, K.V. Donohue, R.M. Roe, M.A. Bourham, Journal of Applied Polymer Science, 103 (2007) 1911-1917. 
[21] M.H. Han, J.P. Jegal, K.W. Park, J.H. Choi, H.K. Baik, J.H. Noh, K.M. Song, Y.S. Lim, Surface \& Coatings Technology, 201 (2007) 4948-4952. 


\section{Figure captions}

Figure 1.- 3D surface plot showing variation of the T-peel force in terms of the plasma treatment rate and the nozzle-substrate distance for ionomer-polycarbonate adhesion joints.

Figure 2.- 3D surface plot showing variation of the shear force in terms of the plasma treatment rate and the nozzle-substrate distance for ionomer-polycarbonate adhesion joints.

Figure 3.- SEM images of fractured surfaces from T-peel tests of ionomerpolycarbonate adhesion joints $(100 \mathrm{x})$ at a constant plasma treatment rate of $100 \mathrm{~mm} \mathrm{~s}^{-1}$ for different nozzle-susbtrate distances: a) $6 \mathrm{~mm}$, b) $10 \mathrm{~mm}$, c) $14 \mathrm{~mm}$ and d) $20 \mathrm{~mm}$.

Figure 4.- SEM images of fractured surfaces from T-peel tests of ionomerpolycarbonate adhesion joints (100x) at a constant nozzle-substrate distance of $10 \mathrm{~mm}$ for different plasma treatment rates: a) $100 \mathrm{~mm} \mathrm{~s}^{-1}$ and b) $1000 \mathrm{~mm} \mathrm{~s}^{-1}$.

Figure 5.- SEM images of fractured surfaces from shear tests of ionomer-polycarbonate adhesion joints (50x) at a constant plasma treatment rate of $100 \mathrm{~mm} \mathrm{~s}^{-1}$ for different nozzle-susbtrate distances: a) $6 \mathrm{~mm}$, b) $10 \mathrm{~mm}$, c) $14 \mathrm{~mm}$ and d) $20 \mathrm{~mm}$.

Figure 6.- SEM images of fractured surfaces from shear tests of ionomer-polycarbonate adhesion joints (50x) at a constant nozzle-substrate distance of $10 \mathrm{~mm}$ for different plasma treatment rates: a) $100 \mathrm{~mm} \mathrm{~s}^{-1}$ and b) $1000 \mathrm{~mm} \mathrm{~s}^{-1}$. 
Table 1. Contact angle measurements of different ionomer samples treated with plasma at different treatment conditions.

\begin{tabular}{|c|c|c|c|}
\hline \multirow{2}{*}{$\begin{array}{c}\text { Distance } \\
\text { (mm) }\end{array}$} & \multirow{2}{*}{$\begin{array}{c}\text { Plasma speed } \\
\text { (mm/s) }\end{array}$} & \multicolumn{2}{|c|}{ Contact angle measured with WATER } \\
\hline & & $\theta$ & $\sigma$ \\
\hline 0 & 0 & 77,6 & 1,2 \\
\hline \multirow{5}{*}{6} & 100 & 24,6 & 1,8 \\
\hline & 300 & 47,7 & 1,4 \\
\hline & 500 & 53,5 & 1,4 \\
\hline & 700 & 58,6 & 1,2 \\
\hline & 1000 & 63,8 & 1,2 \\
\hline \multirow{5}{*}{10} & 100 & 43,1 & 1,5 \\
\hline & 300 & 52,0 & 0,9 \\
\hline & 500 & 59,6 & 1,1 \\
\hline & 700 & 63,7 & 1,0 \\
\hline & 1000 & 67,8 & 0,5 \\
\hline \multirow{5}{*}{14} & 100 & 59,1 & 0,6 \\
\hline & 300 & 62,3 & 0,6 \\
\hline & 500 & 64,7 & 0,5 \\
\hline & 700 & 68,1 & 0,6 \\
\hline & 1000 & 70,8 & 0,5 \\
\hline \multirow{5}{*}{20} & 100 & 60,1 & 0,8 \\
\hline & 300 & 65,5 & 0,9 \\
\hline & 500 & 68,3 & 1,1 \\
\hline & 700 & 71,6 & 1,0 \\
\hline & 1000 & 75,6 & 0,6 \\
\hline
\end{tabular}




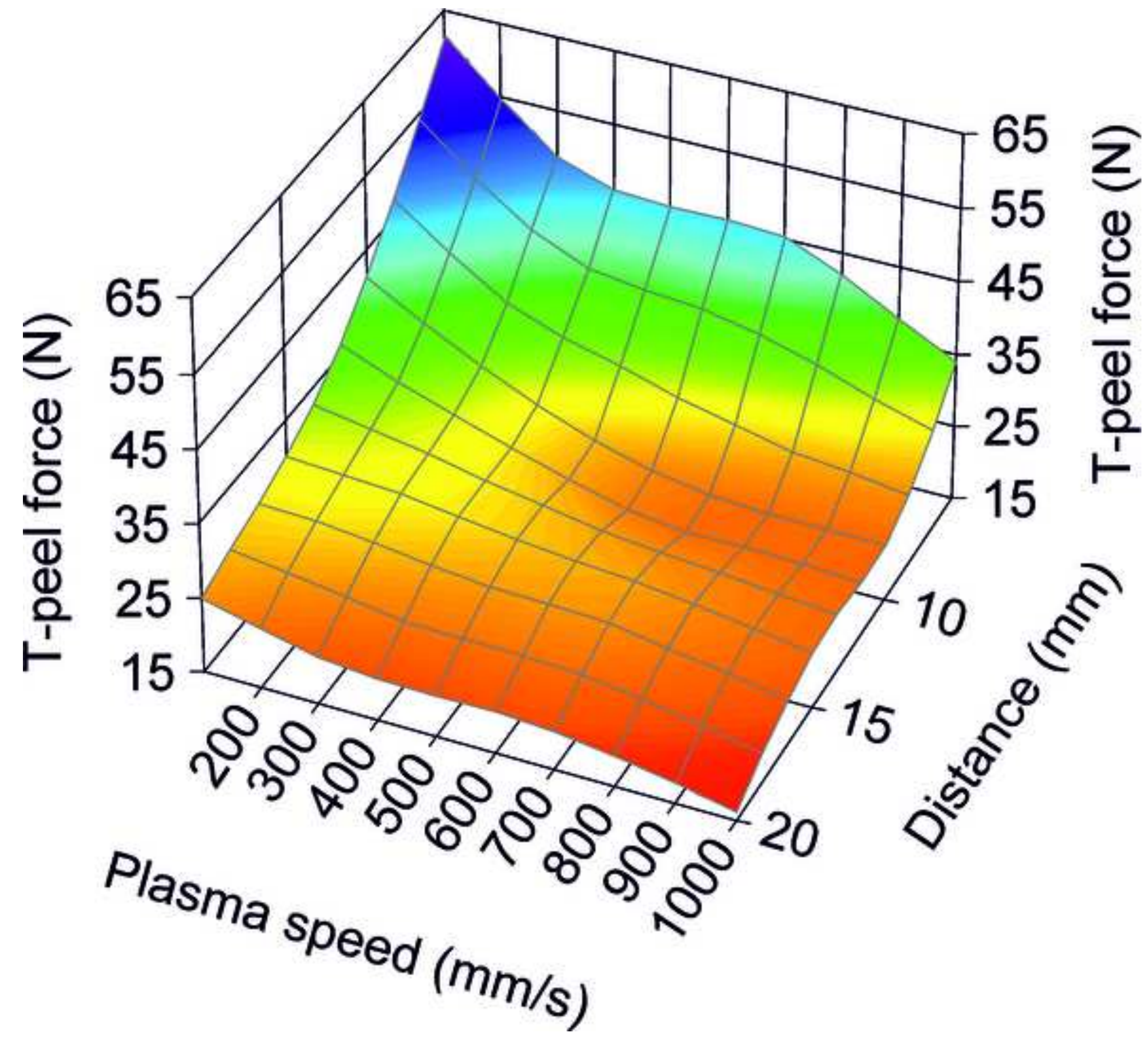




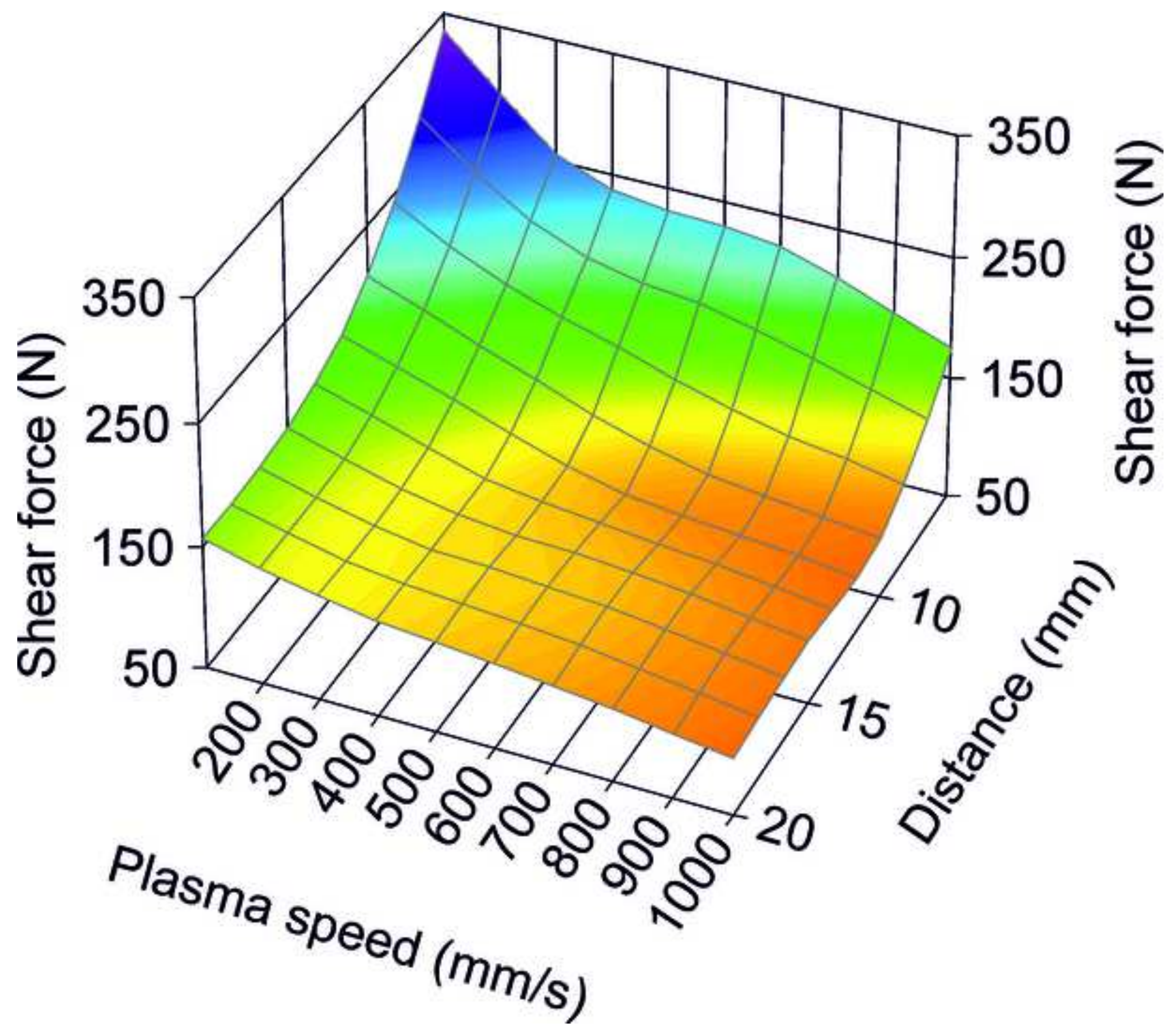


Click here to download high resolution image
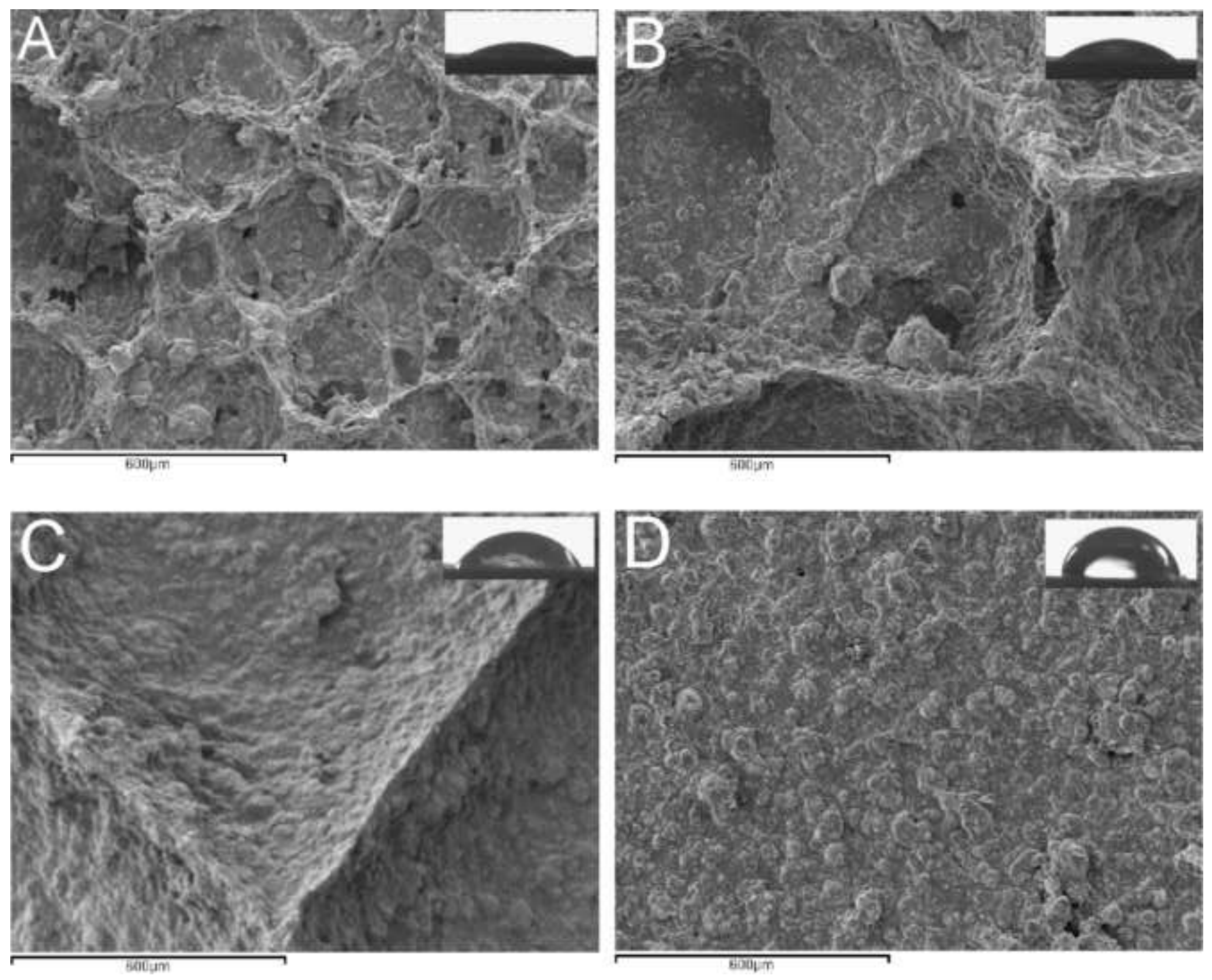
Click here to download high resolution image
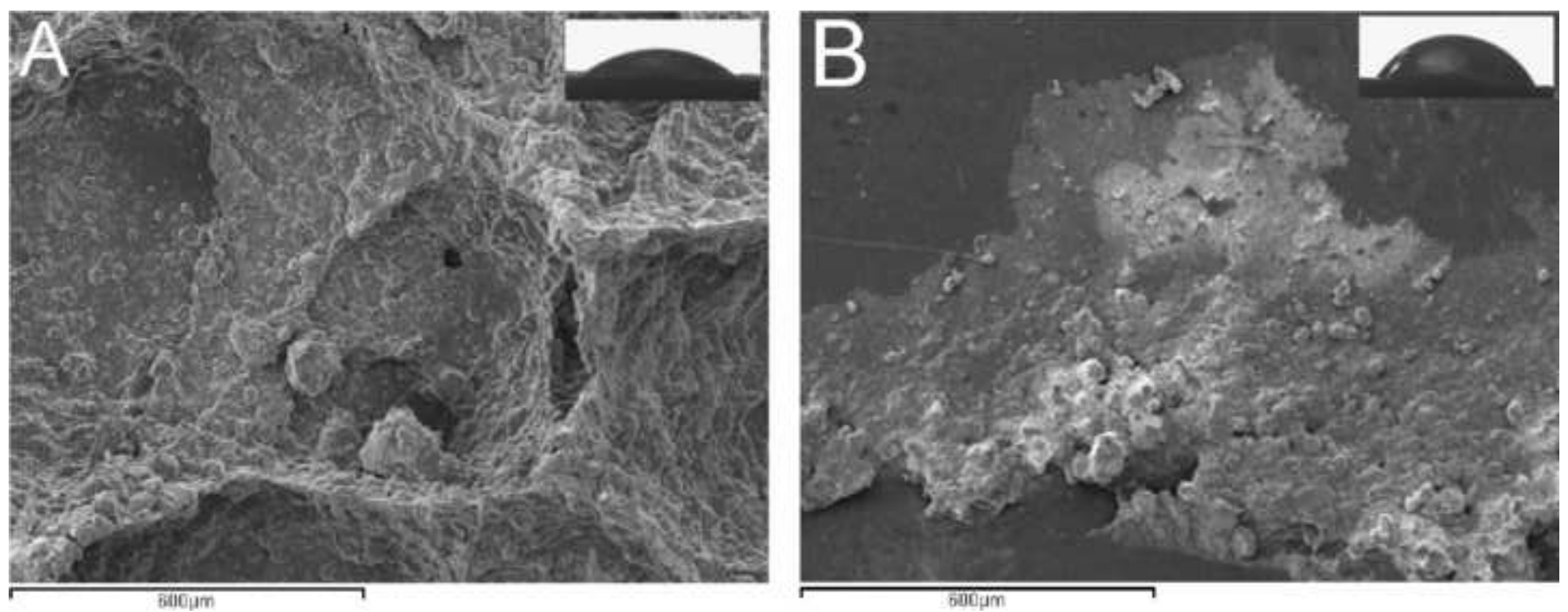

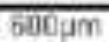

6incum 
Click here to download high resolution image
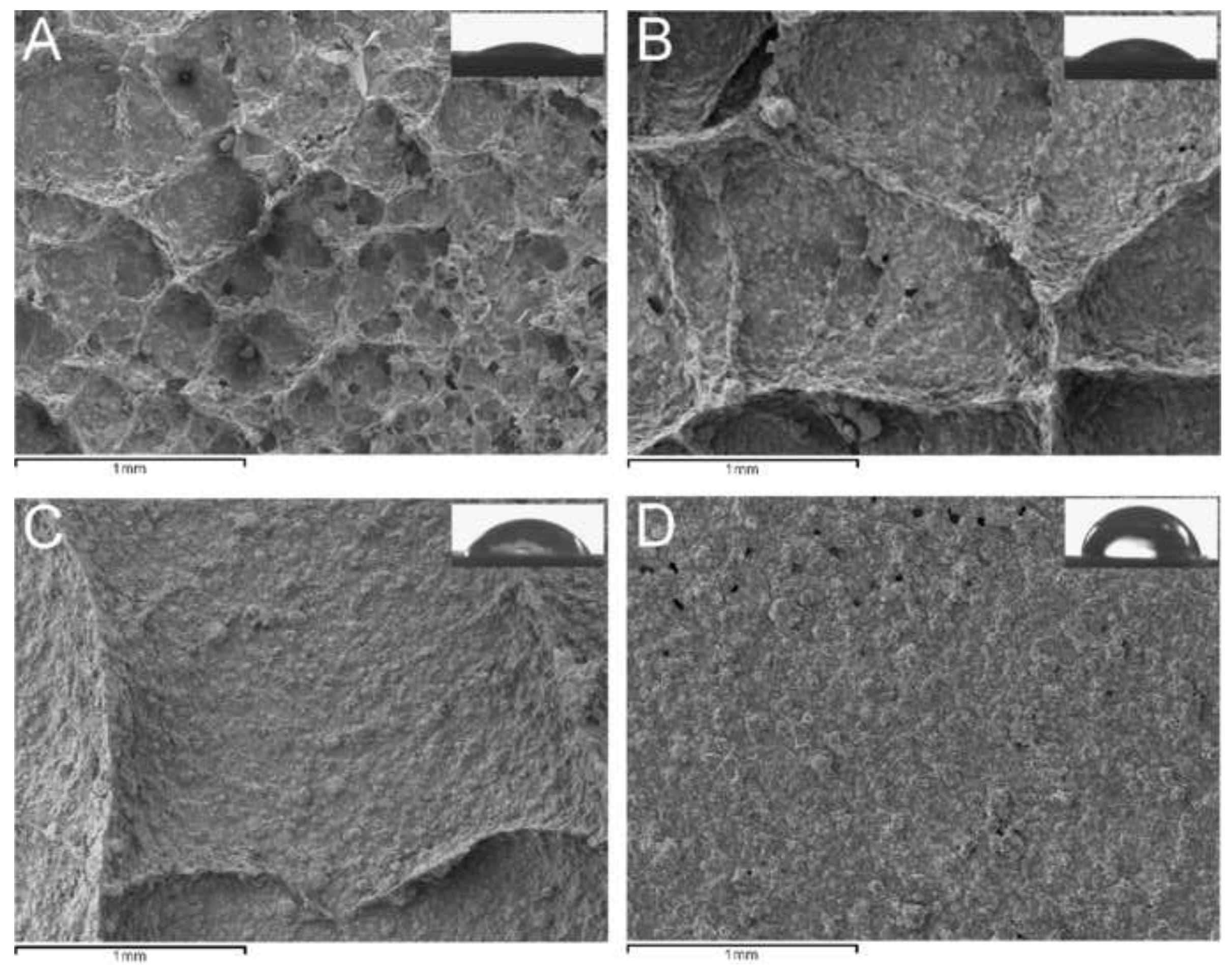

$1 \mathrm{~mm}$ 
Click here to download high resolution image
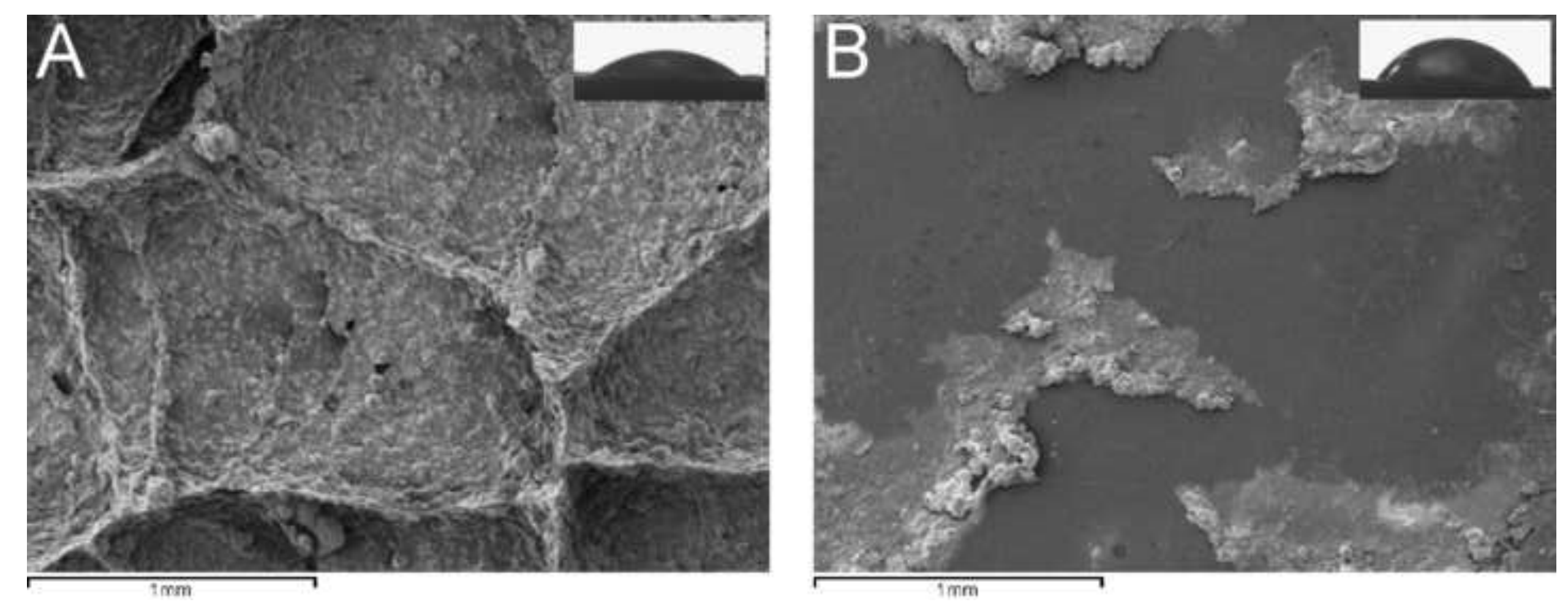

$1 \mathrm{~mm}$

$1 \mathrm{~mm}$ 